\title{
Grapevine virology in the third-generation sequencing era: From virus detection to viral epitranscriptomics
}

Vahid J. Javaran ${ }^{1,2}$, Peter Moffett ${ }^{2}$, P. Lemoyne ${ }^{1}$, Dong $\mathrm{Xu}^{1}$, C. R. Adkar-Purushothama ${ }^{3}$, Mamadou L. Fall ${ }^{1 *}$

${ }^{1}$ Saint-Jean-sur-Richelieu Research and Development Centre, Agriculture and Agri-Food Canada, Saint-Jean-surRichelieu, Quebec, QC J3B 3E6, Canada; vahid.jalalijavaran@agr.gc.ca; pierre.lemoyne@canada.ca; dong.xu@canada.ca

${ }^{2}$ Département de Biologie, Centre SÈVE, Université de Sherbrooke, Sherbrooke, Québec, QC J1K 2R1, Canada; Peter.Moffett@USherbrooke.ca

${ }^{3}$ Département de Biochimie, Faculté de médecine des sciences de la santé, 3201 rue Jean-Mignault, Sherbrooke, Québec, J1E 4K8, Canada; charith.raj.adkar.purushothama@usherbrooke.ca

*Corresponding author: mamadoulamine.fall@ canada.ca; Tel.: 579-224-3024 (M.L.F.)

\begin{abstract}
Among all economically important plant species in the world, grapevine (Vitis vinifera L.) is the most cultivated fruit plant. It has a significant impact on the economies of many countries through wine and fresh and dried fruit production. In recent years, the grape and wine industry has been facing outbreaks of known and emerging viral diseases across the world. Although highthroughput sequencing (HTS) has been used extensively in grapevine virology, the application and potential of third-generation sequencing have not been explored in understanding grapevine viruses and their impact on the grapevine. Nanopore sequencing, a third-generation technology, can be used for direct sequencing of both RNA and DNA with minimal infrastructure. Compared to other HTS methods, the MinION nanopore platform is faster and more cost-effective and allows for long-read sequencing. Due to the size of the MinION device, it can be easily carried for field viral disease surveillance. This review article discusses grapevine viruses and their diagnostic methods, the principle of nanopore sequencing technology and its application in grapevine virus detection, virus-plant interactions, as well as the characterization of viral RNA modifications.

Keywords: Grapevine, Viral Disease, Diagnostic Methods, RNA Sequencing, Nanopore Sequencing Technology, RNA modifications
\end{abstract}




\section{Introduction}

In 2020, over 7.3 million hectares of agricultural land worldwide were planted with grapevines. The economies of many countries are influenced by wine, table grape, raisin, seed oil, alcoholic beverage, and vinegar production [1], as well as associated tourism activities. At present, most cultivated grapevines belong to varieties of $V$. vinifera from Eurasia [2,3]. Climate change and the global movement of plant material on a large scale have led to the emergence of new viral diseases, which has become a serious concern in plant production. Indeed, the global negative economic impact of viral diseases on plant products has been estimated at $\$ 30$ billion annually in 2014 [4]. The economic impact of viral infections in grapevine production are considerable. For instance, grapevine leafroll disease (GLRD) can have an adverse economic effect of between \$29,902 and $\$ 226,405$ per hectare [5]. In addition, the average yield loss during GLRD outbreaks in a vineyard can vary between $15 \%$ and $20 \%$ and is sometimes as high as $40 \%$ [6].

More than 80 viruses from 17 families and 34 genera can infect grapevine (Table 1). Approximately half of these viruses result in viral diseases that can be classified into four major classes: rugose wood complex, leafroll, leaf degeneration, and fleck disease. In recent years, new viral species, such as Grapevine red blotch virus and Grapevine Pinot gris virus, as well as new strains of known viruses have been identified and detected through high-throughput sequencing (HTS) technologies. These viruses cause substantial negative impacts on grapevine production by reducing vine growth, fruit production, and fruit quality [7-10]. High-throughput sequencing technologies have increased the knowledge of molecular evolution and pathological properties of grapevine viruses during the last decade. However, there are many unanswered questions about the biological and epidemiological features of individual grapevine viruses in mixed infections, the molecular basis of plant-virus interactions, and grapevine virome complexity. In this review, we briefly introduce the conventional diagnosis methods that have been used for grapevine virus detection, followed by a discussion of the principle and application of nanopore technology to several areas of research in grapevine virology. 
Table 1. List of viruses identified in grapevine (updated from Fuchs 2020)

\begin{tabular}{|c|c|c|c|c|c|}
\hline Genome & Family & Genus & Species & Virion shape & Disease \\
\hline \multirow[t]{9}{*}{ (+)ssRNA } & Alphaflexiviridae & Potexvirus & Potato virus $X(\mathrm{PVX})$ & Filamentous & None \\
\hline & & Foveavirus & $\begin{array}{l}\text { Grapevine rupestris stem pitting-associated virus } \\
\text { (GRSPaV) } \\
\text { Grapevine virus } T(\mathrm{GVT})\end{array}$ & Filamentous & $\begin{array}{l}\text { Rugose wood } \\
\text { Unknown }\end{array}$ \\
\hline & & Trichovirus & $\begin{array}{l}\text { Grapevine berry inner necrosis virus (GINV) } \\
\text { Grapevine Pinot gris virus (GPGV) }\end{array}$ & Filamentous & $\begin{array}{l}\text { Berry inner necrosis } \\
\text { leaf deformation and } \\
\text { mottling }\end{array}$ \\
\hline & Bromoviridae & Alfamovirus & Alfalfa mosaic virus (AMV) & Bacilliform & Yellow mosaic \\
\hline & & Anulavirus & $\begin{array}{l}\text { Amazon lily mild mottle virus (ALiMMV) } \\
\text { Grapevine line pattern virus (GLPV) }\end{array}$ & Isometric & $\begin{array}{l}\text { None } \\
\text { Line pattern }\end{array}$ \\
\hline & & Cucumovirus & Cucumber mosaic virus (CMV) & Isometric & Unknown \\
\hline & & Ilarvirus & $\begin{array}{l}\text { Grapevine angular mosaic virus }(\mathrm{GaMoV}) \\
\text { Grapevine virus } S(\mathrm{GVS})\end{array}$ & $\begin{array}{l}\text { Isometric } \\
\text { Unknown }\end{array}$ & $\begin{array}{l}\text { Angular mosaic } \\
\text { Unknown }\end{array}$ \\
\hline & Closteroviridae & Closterovirus & Grapevine leafroll-associated virus 2 (GLRaV2) & Filamentous & Leafroll/ Incompatibility \\
\hline & & Ampelovirus & $\begin{array}{l}\text { Grapevine leafroll-associated virus } 1 \text { (GLRaV1) } \\
\text { Grapevine leafroll-associated virus } 3 \text { (GLRaV3) } \\
\text { Grapevine leafroll-associated virus } 4 \text { (GLRaV4) } \\
\text { Grapevine leafroll-associated virus } 13 \text { (GLRaV13) }\end{array}$ & Filamentous & Leafroll \\
\hline
\end{tabular}




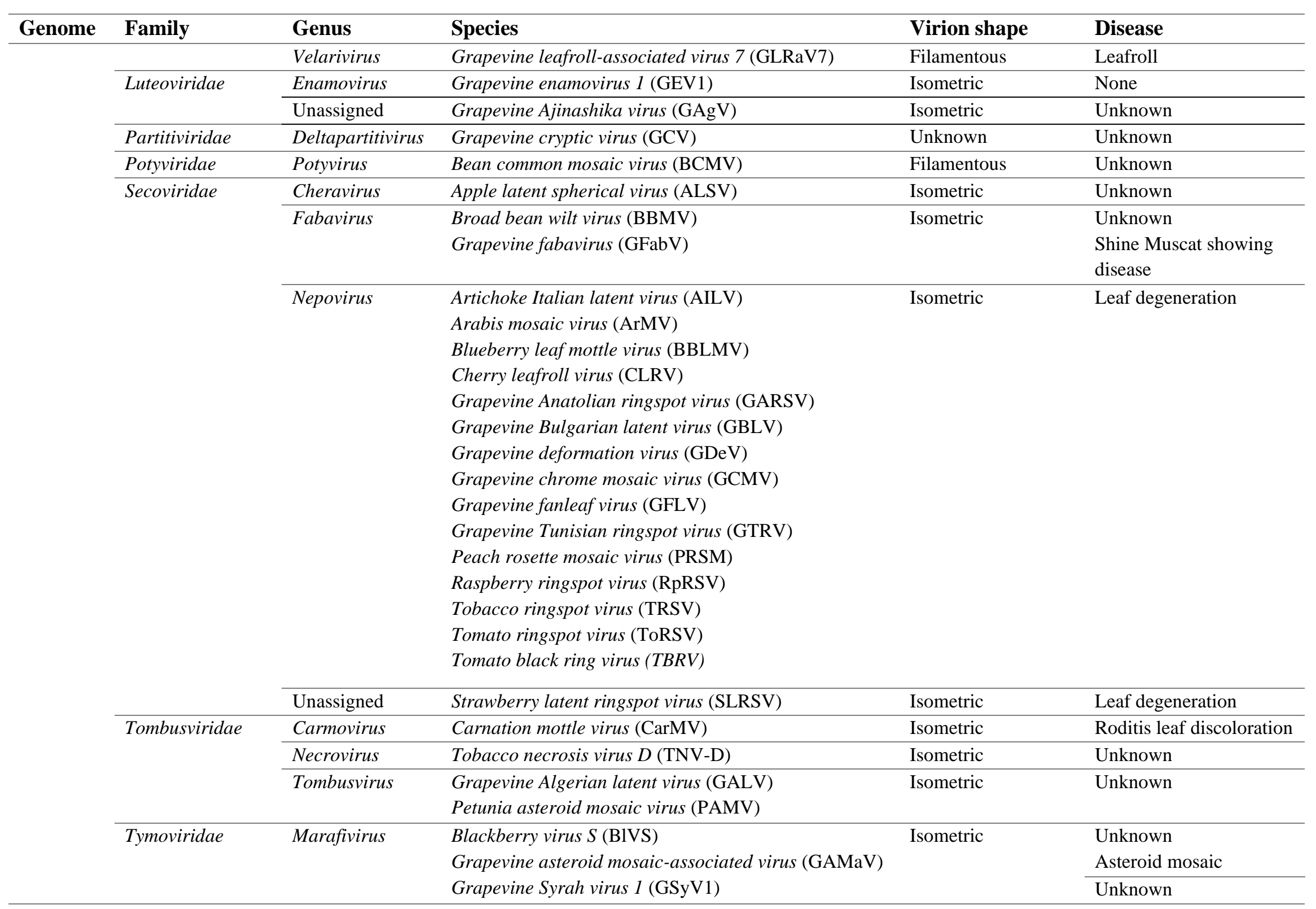




\begin{tabular}{|c|c|c|c|c|c|}
\hline Genome & Family & Genus & Species & Virion shape & Disease \\
\hline & & Maculavirus & Grapevine fleck virus (GFkV) & Isometric & Fleck \\
\hline & & & Grapevine red globe virus (GRGV) & & Unknown \\
\hline & & Gratylivirus & Grapevine-associated tymo-like virus (GaTLV) & Isometric & Unknown \\
\hline & Virgaviridae & Tobamovirus & Grapevine virga-like virus (GVLV) & Rod & Unknown \\
\hline & & & Tobacco mosaic virus (TMV) & & \\
\hline & & & Tomato mosaic virus (ToMV) & & \\
\hline & Unassigned & Idaeovirus & Raspberry bushy dwarf virus (RBDV) & Isometric & Unknown \\
\hline & & Sobemovirus & Sowbane mosaic virus (SoMV) & Isometric & Unknown \\
\hline & & Virtovirus & Grapevine virus satellite (GV-Sat) & Isometric & Unknown \\
\hline & & Unassigned & Grapevine labile rod-shaped virus (GLRSV) & Rod & Unknown \\
\hline & & & Grapevine stunt virus (GSV) & Isometric & \\
\hline$(-)$ ssRNA & Bunyaviridae & Tospovirus & Tomato spotted wilt virus (TSWV) & Isometric & Unknown \\
\hline & Phenuiviridae & Rubodvirus & Grapevine Garan dmak virus (GGDV) & Isometric & Unknown \\
\hline & & & Grapevine Muscat rose virus (GMRV) & & \\
\hline dsRNA & Endornaviridae & Endornavirus & Grapevine endophyte endornavirus (GEEV) & $\begin{array}{l}\text { Does not have any } \\
\text { gene for capsid } \\
\text { protein, no virion }\end{array}$ & None \\
\hline & Reoviridae & Oryzavirus (?) & Grapevine Cabernet Sauvignon reovirus (GCSV) & Isometric & Unknown \\
\hline ssDNA & Geminiviridae & Begomovirus & Grapevine begomovirus A (GBVA) & Twinned & Unknown \\
\hline & & Grablovirus & Grapevine red blotch virus (GRBV) & Twinned & Red blotch \\
\hline & & & Wild Vitis latent virus 1 (WVV1) & & \\
\hline & & Unassigned & Grapevine geminivirus A (GGVA) & Twinned & Unknown \\
\hline & & & Temperate fruit-decay-associated virus (TFDaV) & & \\
\hline dsDNA & Caulimoviridae & Badnavirus & Grapevine vein clearing virus (GVCV) & Bacilliform & Vein clearing \\
\hline & & & Grapevine badnavirus 1 (GBV1) & & Unknown \\
\hline & & & $\begin{array}{l}\text { Grapevine Roditis leaf discoloration-associated virus } \\
\text { (GRLDaV) }\end{array}$ & & Roditis discoloration \\
\hline
\end{tabular}




\section{The diagnostic toolbox in grapevine virology}

Early and easy identification of viruses allows growers to take quick actions and effective sanitary measures, such as removing affected vines, limiting the movement of agricultural machinery, cleaning tools, controlling vectors to limit the spread of viruses, and providing improved tools for certification procedures of propagative materials before importing germplasm $[9,11]$. Some common diagnostic tools used for monitoring and detecting grapevine viruses are described below.

Multispectral or hyperspectral imaging is a new technology that captures wavelengths reflected by plants (symptomatic, asymptomatic, and healthy) on an electromagnetic spectrum (visible [VIS; 400-700 nm], near-infrared [NIR; 700-1000 nm], and short-wave infrared range [SWIR; 1000$2500 \mathrm{~nm}$ ]) through spectral sensors [12]. Abiotic and biotic stresses such as viruses alter the biochemical processes of plant leaves, as well as structural components of the cells, which influence the leaf spectral patterns. These spectral patterns, either whole (hyper) or selected (multi) wavelengths, can be captured and analyzed with a machine learning model. As such, the detection of viruses and monitoring of dynamic symptom development are possible through this technology [13].

Other diagnostic methods that have been widely used for grapevine virus detection are serological diagnostic methods such as enzyme-linked immunosorbent assay (ELISA), lateral flow immunoassay (LFIA), direct immune-printing (DIP), immune filtration with magnetic nanoparticles, and immunosorbent electron microscopy (ISEM). As easy, accurate, and cheap diagnostic methods, these diagnostic methods are based on monoclonal or polyclonal antibodies binding to viral particles. In-depth reviews of such serological diagnostic methods and spectral imaging technologies are discussed elsewhere [13-15]. Several kinds of ELISA methods are used for plant virus detection, such as double antibody sandwich ELISA (DAS-ELISA), direct and indirect ELISA, and Affimer protein (AP)-based ELISA. Briefly, in indirect ELISA, a commonly used ELISA for virus detection, a microtitre plate is coated with the sap from an infected plant. A primary antibody is added, which binds to viral antigens. Any unbound antibody is washed off, and the secondary antibody, conjugated to an enzyme, is added. The latter allows for detection through the production of a chromogenic product. This method can also be used for virus quantification by quantifying the chromogenic product by spectrophotometer $[16,17]$. Five major suppliers have designed more than 70 ELISA reagent sets for detecting 18 different viruses in 
grapevine samples [14]. However, antibody preparation is labor-intensive and expensive, and the possibility of false positive and negative results in these kinds of dignostics is high [18]. Furthermore, these kinds of tests can only confirm the presence of known viruses for which antibodies are available.

Several diagnostic techniques based on nucleic acid amplification, such as standard PCR, reverse transcription PCR (RT-PCR), quantitative RT-PCR (RT-qPCR), multiplex PCR, nested PCR, or loop-mediated isothermal amplification (LAMP), are also used for grapevine virus detection. Although these methods are more sensitive, specific, and time-saving than serological methods, they have several limitations. These include false negative results due to the presence of polymerase-inhibiting phenolic and polysaccharide compounds or other contaminants found in samples, as well as the requirement for equipment such as real-time PCR machines and sometime the necessity for analysis on agarose gels. In addition, in order to design specific primers, prior knowledge of viral genomes is needed. Several grapevine viruses, such as Grapevine fanleaf virus (GFLV), Arabis mosaic virus (ArMV), Grapevine leafroll-associated virus 3 (GLRaV-3), Grapevine fleck virus (GFkV), Grapevine Red Blotch-associated Virus (GRBV), GLRaV-1-5, -7, and -9, Grapevine virus A (GVA), Grapevine virus B (GVB) and Grapevine virus D (GVD), have been detected through PCR amplification-based methods in the laboratory or on-site [19]. Some techniques, in particular LAMP, have improved the nucleic acid amplification-based detection of grapevine viruses. Indeed, high speed and specificity, resistance to inhibitors, and colorimetric detection features have made LAMP a popular diagnostic method [19]. LAMP uses a set of four or six different primers from various regions of a viral genome. A strand displacement DNA polymerase replicates various stem-loop complexes with multiple stem lengths, and through a specific colorimetric assay, viral sequences are detected [20]. The LAMP technique has been used to detect GLRaV-3 and GFLV in vineyards without requiring a thermal cycler to run the reaction. The LAMP technique was found to be as sensitive as nested PCR and an alternative option for ELISA to detect GLRaV-3 quickly [21]. In another study, RT-LAMP was found to be more sensitive than DAS-ELISA, RT-PCR, or immuno-RT-PCR for GFLV detection [22].

Although several PCR amplification-based methods can detect a limited number of viruses in a single reaction, for detecting multiple viruses simultaneously, microarrays can be used. The use of DNA microarrays to detect viruses is based on the hybridization of viral nucleic acids to DNA probes specific to different viruses attached to a solid matrix. The latter is then incubated with 
fluorescently or radioactively labeled RNA or cDNA from infected plants. As such, any labeled viral nucleic acid will hybridize to the probes and indicate the presence of the virus [23]. In 2010, an array containing 570 unique probes against species-specific regions of 44 plant viral genomes was designed, and 10 grapevine viruses from different samples were detected, with results being similar to RT-PCR results [24].

With the advent of HTS, the characterization and investigation of known and novel viruses have been made possible. Although many viruses have been detected and identified by total RNA or DNA sequencing, the abundance of viral sequences relative to cellular RNAs is often very low, and detection of low-titer viruses may be compromised with HTS. Some purification methods have been developed to concentrate viral nucleic acids, thus improving the abundance of viral sequences submitted to HTS. These methods include virion-associated nucleic acids (VANAs) and doublestranded RNA (dsRNA) extraction, small interfering RNA (siRNA), and rRNA depleted and polyadenylated RNA isolation. Many known and novel grapevine viruses have been detected and identified with these methods, such as Grapevine Syrah virus 1 (GSyV-1), through total RNA and dsRNA sequencing, Grapevine vein-clearing virus (GVCV) and Grapevine Pinot gris virus (GPGV), through small RNA sequencing, Grapevine virus F (GVF) and Grapevine red blotch associated virus (GRBaV), through dsRNA sequencing, and Grapevine Roditis leaf discolorationassociated virus (GRLDaV), through siRNA sequencing [19,25-28]. Although second-generation sequencing has been broadly used in virus identification and detection, several limitations remain, such as read lengths, GC content and amplification biases, laborious and costly library preparation methods, data management, and requirement of sophisticated technical expertise for data analysis $[29,30]$.

\section{Third-generation sequencing platforms}

Through the advent of third-generation sequencing technologies, such as Pac Bio singlemolecule real-time (SMRT) sequencing and Oxford Nanopore sequencing, some of the aforementioned limitations of second-generation sequencing have been addressed. In SMRT sequencing, a double-stranded DNA template is circularized, called SMRTbell, through the ligation of hairpin adapters to both ends. The template and DNA polymerase are immobilized at the bottom of a chip, named SMRT Cell, consisting of many photonic nanostructures, zero mode waveguides (ZMWs). The latest generation of SMRT sequencer has one million ZMWs per SMRT 
Cell. Single-molecule real-time sequencing does not require an amplification step, and the template is sequenced based on its complementary strand synthesis by DNA polymerase with fluorescently labeled dNTPs [31]. After loading a SMRTbell library into a SMRT Cell, the DNA polymerase starts replicating the DNA from the adapter region of the SMRTbell using four fluorescently labeled A, T, G, and C nucleotides. Each nucleotide produces a signature light pulse that is captured as a "movie." Light pulses are then basecalled to the nucleotide sequence, and each sequence obtained from a ZMW is referred to as a Continuous Long Read (CLR) [32]. The Sequel II SMRT sequencer can produce reads as long as $50 \mathrm{~kb}$. Although library preparation and sequencing running time of SMRT sequencing are shorter than short-read sequencing technologies, SMRT reads typically have a high error rate $(\sim 15 \%)$ [33]. However, PacBio has released a new sequencing system, circular consensus sequencing (CCS), which produces highfidelity reads (HiFi) with $99.8 \%$ accuracy and an average length of $13.5 \mathrm{~kb}$. In this system, since the DNA template is circular, the polymerase can start to synthesize several subreads from a DNA template continuously, and a single-molecule circular consensus sequence (known as HiFi) with high accuracy can be achieved [34].

In 2014, a pocket-sized commercial sequencer device, MinION, was introduced by Oxford Nanopore Technologies (ONT). The concept of nanopore sequencing was initially described in 1996 [35]. Nanopore technology is based on directly detecting each base of a single strand of nucleotides (DNA or RNA) as it passes through a nanopore protein, MspA, which is stabilized in an electrically resistant polymer membrane. The passage of single strands of nucleotide through MspA nanopore is mediated by a helicase motor protein that unwinds double-stranded DNA and controls the translocation speed. At the same time, an ionic current is passed across the membrane, and when the nucleotides cross the nanopore, a biosensor records the variations in ionic current. The presence of each of the four possible different bases induces a specific fluctuation pattern in the ionic current, and a basecaller software can then translate these fluctuations in current to sequence information (Figure 1A) [36]. MinKNOW, as the operating software, controls nanopore sequencing devices and performs several tasks, such as data acquisition, real-time analysis and feedback, local basecalling, and data streaming. In addition, MinKNOW has several options to adjust run parameters, sample identification, and tracking, and monitoring chemistry efficiency during the run. 
Nanopore sequencing technology has lower throughput and high error rates compared with second-generation sequencing technologies. However several features, such as the small size of the sequencer, ease of library preparation, low sequencing cost and short run times, make it an interesting tool for the surveillance of viruses and other pathogens [37]. To date, two different nanopore chemistries, R9 and R10, which use nanopore proteins with properties conducive to different applications, have been used for designing nanopore flow cells. In nanopore sequencing, RNA/DNA libraries are loaded onto flow cells, which are composed of contain three parts: sensing chemistry (R9 and R10), sensor array (containing the nanopores), and electronics (applicationspecific integrated circuit (ASIC), heat mat, and connector pins). There are three different flow cells (MinION, PromethION, and Flongle), which differ in sequencing throughput and number of nanopores (Table 2). MinION flow cell possess 512 channels; each channel contains four nanopores which are stabilized within four microwells. PromethION and Flongle flow cell have 2675 and 128 channels, respectively, which can be used for large and small genomes or genes, respectively. These combinations of flow cell types and sequencer machines allow for flexibility in choosing the most appropriate strategy for sequencing with respect to choosing, for example, high coverage of single samples versus multiplexing. These platforms have sequencing accuracy rates between $97-98.3 \%$, depending on flow cell chemistry and the mode of basecalling step.

Table 2. General properties of commercial nanopore sequencer machines and their flow cells

\begin{tabular}{cccccc}
\hline Sequencer & Flow cell & $\begin{array}{c}\text { Maximum yield } \\
\text { per flow cell }(\mathrm{Gb})\end{array}$ & $\begin{array}{c}\text { Flow cell } \\
\text { number in each } \\
\text { running }\end{array}$ & $\begin{array}{c}\text { Maximum } \\
\text { running time } \\
\text { (hours) }\end{array}$ & $\begin{array}{c}\text { Nanopore channel } \\
\text { number in each } \\
\text { flow cell }\end{array}$ \\
\hline MinION Mk1B/Mk1C & $\begin{array}{c}\text { MinION (R9.4.1 or } \\
\text { R10.3) }\end{array}$ & $\begin{array}{c}50 \text { for MinION/ } \\
2.8 \text { for Flongle }\end{array}$ & 1 & $\begin{array}{c}72 \text { for MinION/ } \\
16 \text { for Flongle }\end{array}$ & $\begin{array}{c}512 \text { for MinION/ } \\
126 \text { for Flongle }\end{array}$ \\
\hline GridION & MinION (R9.4.1 or & 50 for MinION/ & 5 & 72 for MinION/ & 512 for MinION/ \\
& R10.3) /Flongle & 2.8 for Flongle & & 16 for Flongle & 126 for Flongle \\
\hline PromethION 24/48 & PromethION & 290 & $24 / 48$ & 72 & 2675 \\
& & & & &
\end{tabular}

In recent years, ONT has improved the read quality of nanopore sequencing by changing the chemical reagents used in library preparation kits and flow cells and developing improved algorithms for basecalling. For example, higher raw read accuracy (98.3\%) was achieved by a new basecaller software, Bonito [38]. Additional improvements include sequencing kits based on a new chemistry, Q20+, which has been tested in nanopore flow cells and will be released in the near 
future. This technology uses a refined motor protein (E8.1), which increases raw read accuracy to 99.3\% [39]. Other experiments are being tested to improve nanopore sequencing. For example, selective sequencing will soon be possible, which means by changing the DNA orientation sequencing, the length of each fragment can be measured by nanopore. Then, the shorter fragment is ejected from the nanopore, and only desirable fragments can be sequenced. In the current sequencing mechanism, the DNA strand is passed and sequenced through the nanopore from the top environment of the nanopore to the area underneath, referred to as an "Inny" orientation. In contrast, in the Outy orientation, first the DNA strand is passed through the nanopore, and its length is measured. The sequencing step is next performed by reversing the movement of the DNA from the inner to the top environment of the nanopore (Figure 1B). 
A

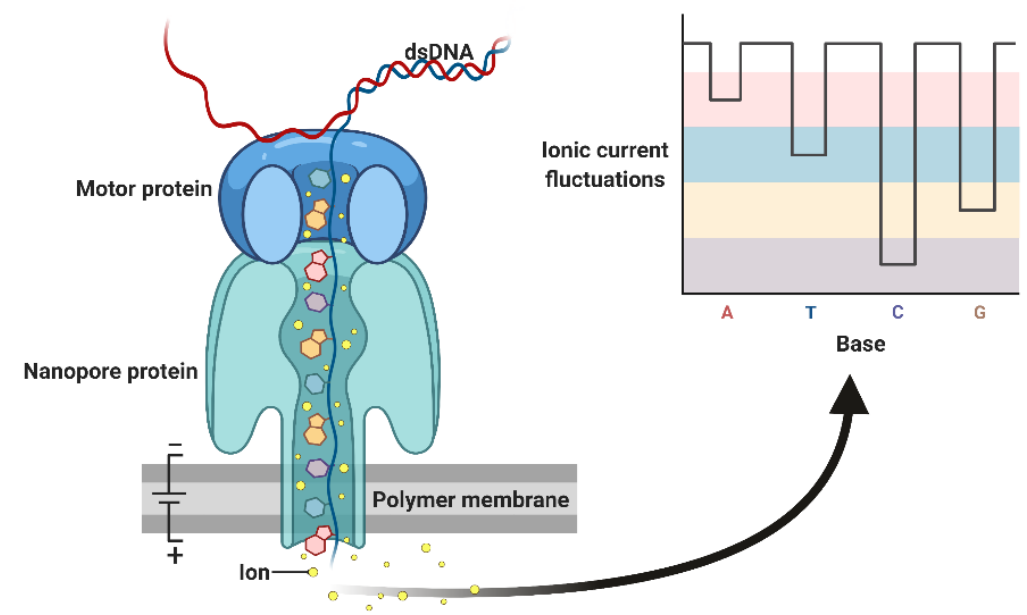

B
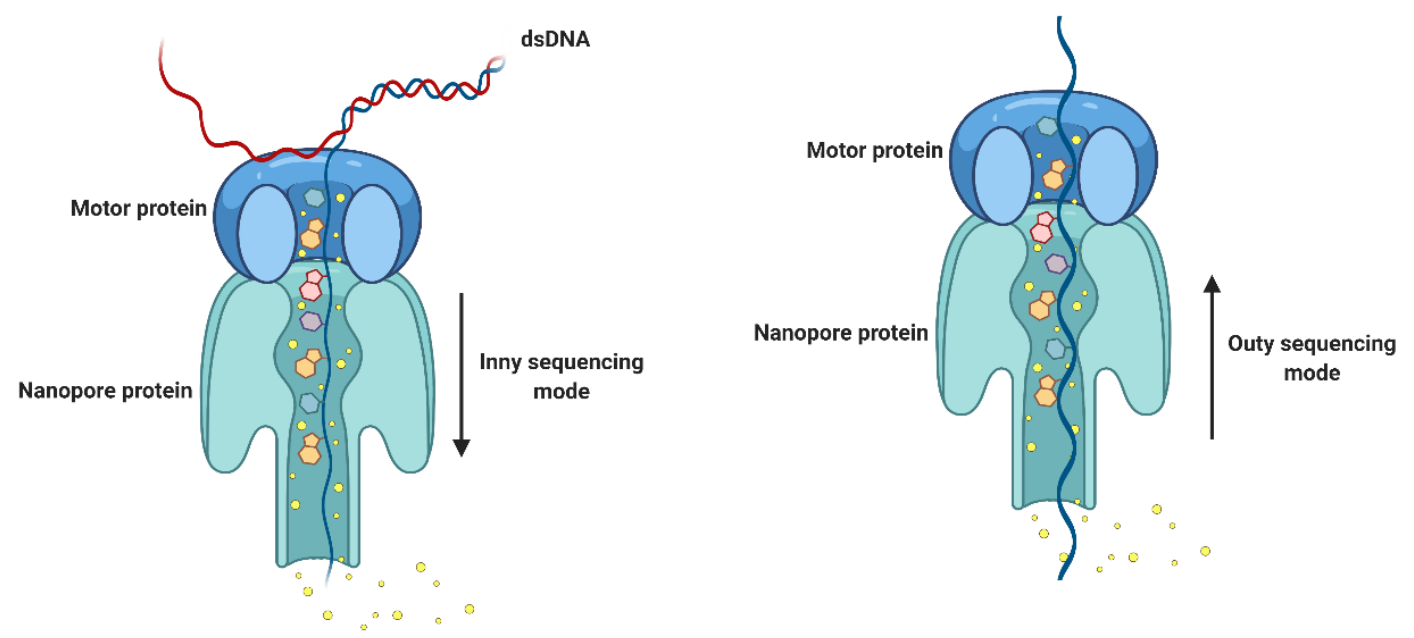

Figure 1. Schematic diagram of Nanopore sequencing technology. A. Double-stranded DNA is unwound by a motor protein. One strand of DNA is passed through a nanopore protein that forms a channel in an artificial membrane to which an ionic current has been applied. The ion current is altered depending on the identity of the base passing through the channel. The resulting fluctuations are decoded and translated to DNA (or RNA) sequence. B. Inny and outy sequencing modes. Adapted from "Nanopore Sequencing", by BioRender.com (2021). Retrieved from https://app.biorender.com/biorender-templates. 


\section{The application of nanopore sequencing to plant virus detection}

The potential of nanopore sequencing for the detection and identification of plant pathogens in field and lab environments has been shown in many different studies. Different library preparation kits with straightforward protocols are available and have been used to detect a number of different viruses from infected plant samples (Table 3). For instance, a field diagnosis system based on nanopore sequencing has been developed to rapidly (3 hours) detect Cassava mosaic begomoviruses in cassava plants [40]. In another study, a comparison between RNA and PCRcDNA nanopore sequencing kits for plum pox virus detection in tobacco samples indicated that nanopore technology could effectively identify plant viruses [37]. However, the results of the latter study showed that the PCR-cDNA sequencing kit could produce longer reads and 400 times more reads than the direct RNA sequencing kit. In addition, the mean quality score and mean read length were higher for the PCR-cDNA sequencing kit compared to the direct RNA sequencing kit [37]. Therefore, based on the goals of the diagnostic or experimental approach, the choice of sequencing kit requires careful consideration.

Positive features of nanopore sequencing, such as quick library preparation protocols, pocketsized sequencer machines, producing many sequences in few hours, and being a cost- and timeeffective method, has the potential to dramatically impact plant pathology, especially in the area of diagnostics. In particular, this technology can be used for parallel sequencing of multiple samples through multiplex barcoding. Our research group at Agriculture and Agri-Food Canada's Saint-Jean-sur-Richelieu Research and Development Centre has been working on optimizing this technology to detect grapevine viruses. Preliminary results indicate that not only is this technology cheaper than HTS but also the diagnostic capabilities are similar to Illumina (unpublished data) and could be an attractive alternative diagnostic tool for grapevine viruses. 
Table 3. List of plant viruses detected using nanopore sequencing technology

\begin{tabular}{|c|c|c|c|c|}
\hline Virus Name & Host Plant & $\begin{array}{l}\text { Nucleic Acids } \\
\text { Extraction }\end{array}$ & Library Preparation Kit & References \\
\hline Sowthistle yellow vein virus (SYVV) & Sonchus oleraceus L. & Total RNA & Direct RNA sequencing & [41] \\
\hline $\begin{array}{c}\text { Cowpea bright yellow mosaic virus } \\
\text { (CoBYMV) }\end{array}$ & Vigna unguiculata & Total DNA & Ligation Sequencing & {$[42]$} \\
\hline Plum pox virus & Prunus persica & Total RNA & Ligation Sequencing & [43] \\
\hline $\begin{array}{c}\text { Wheat streak mosaic virus } \\
\text { (WSMV) } \\
\text { Triticum mosaic virus (TriMV) } \\
\text { Barley yellow dwarf virus (BYDV) }\end{array}$ & Wheat & Total RNA & Ligation Sequencing & [44] \\
\hline $\begin{array}{c}\text { Tomato yellow leaf curl virus } \\
\text { (TYLCV) } \\
\text { Watermelon chlorotic stunt virus } \\
\text { (WmCSV) } \\
\text { Tomato brown rugose fruit virus } \\
\text { (ToBRFV) } \\
\text { Cucumber green mottle mosaic virus } \\
\text { (CGMMV) } \\
\text { Zucchini yellow mosaic virus } \\
\text { (ZYMV) }\end{array}$ & $\begin{array}{c}\text { Solanum } \\
\text { lycopersicum } \\
\text { Cucumis sativus } \\
\text { Citrullus lanatus } \\
\text { Cucurbita moschata }\end{array}$ & $\begin{array}{l}\text { Total RNA } \\
\text { Total DNA }\end{array}$ & $\begin{array}{l}\text { Direct RNA sequencing } \\
\text { Ligation Sequencing }\end{array}$ & {$[45]$} \\
\hline $\begin{array}{l}\text { Dioscorea bacilliform viruses (DBVs) } \\
\text { Yam mild mosaic virus (YMMV) } \\
\text { Yam chlorotic necrosis virus (YCNV) }\end{array}$ & Dioscorea alata & Total RNA & $\begin{array}{c}\text { PCR-cDNA Sequencing } \\
\text { Kit }\end{array}$ & {$[46]$} \\
\hline $\begin{array}{c}\text { Potato virus } Y(\mathrm{PVY}) \\
\text { Potato virus } X(\mathrm{PVX}) \\
\text { Potato virus } S(\mathrm{PVS}) \\
\text { Potato leafroll virus (PLRV) }\end{array}$ & $\begin{array}{c}\text { Solanum tuberosum } \\
\text { L. }\end{array}$ & Total RNA & Ligation Sequencing Kit & [47] \\
\hline $\begin{array}{c}\text { East African cassava mosaic virus } \\
\text { (EACMV) } \\
\text { African cassava mosaic virus } \\
\text { (ACMV) } \\
\text { Tobacco leaf curl virus }(\mathrm{TLCV})\end{array}$ & Manihot esculenta & Total DNA & Rapid Barcoding Kit & {$[40]$} \\
\hline
\end{tabular}

Below, we discuss different library preparation protocols that can be used for the detection and identification of grapevine viruses. In addition, we describe how nanopore sequencing can be used for the identification of different long non-coding RNAs and circular RNAs involved in grapevine virology as well as its potential to study plant or viral RNA modification.

\section{Detection of grapevine RNA viruses by nanopore direct cDNA and RNA sequencing}

Grapevine viruses are represented by many families, including viruses with RNA or DNA genomes [9]. Different types of material, such as total RNA or DNA, double-strand RNAs (dsRNAs), and small interfering RNAs (siRNA) can be targeted for sequencing viruses infecting 
grapevine. Due to the presence of plant RNAs and rRNAs, detecting low-titer viruses is challenging when using total RNAs extraction for sequencing and is also an important consideration if one wishes to reduce sequencing complexity to allow for multiplexing samples [48]. An alternative option for virus sequencing is to use dsRNA. Plant RNA viruses produce dsRNA as an intermediate during their replication. DNA viruses have also been shown to produce dsRNA during infection, possibly due to the action of endogenous RNA-dependent RNA polymerases $[49,50]$. Therefore, dsRNA sequencing increases the overall proportion of viral reads and detection sensitivity [48]. Using this method, we have recently characterized the virome of some grapevine cultivars in several Quebec vineyards, and many viruses were detected by Illumina sequencing [26]. However, dsRNA extraction is time-consuming compared to total RNA extraction, so sometimes for quick virus detection, total RNA extraction is preferred.

Eighteen different reagent kits for nanopore sequencing of various genetic materials have been commercialized, and four of them were used in different plant virus detection projects (Table 3). The direct cDNA sequencing kit with multiplexing capability is an option to sequence cDNA synthesized from purified dsRNA or total RNAs. Although cDNA synthesis in this protocol is based on the strand switching procedure and oligo dT-containing VN primers ( $\mathrm{V}$ for $\mathrm{dA}, \mathrm{dC}$, or $\mathrm{dG}$ and $\mathrm{N}$ for $\mathrm{dA}, \mathrm{dC}, \mathrm{dG}$, or $\mathrm{dT}$ ), cDNA can also be synthesized using random hexamer primers to target both poly(A) and non-poly(A) viral RNAs (Figure 2). The latter is an important element to consider, as many RNA viruses to not produce poly(A) tailed RNAs. Through poly(A) tailing, the enrichment of poly(A) and non-poly(A) viral RNAs is also possible, but cDNA synthesis based on the strand-switching mechanism VN primers can produce internal priming and templateswitching artifacts. In the case of internal priming, the initiation of transcription is not from the poly(A) tail, and the poly(T) primer anneals to an adenine-rich region (six or more consecutive adenines, or 12 adenines out of 20 nucleotides) of the transcript, and an internal priming artifact is elongated. With template-switching artifacts, the DNA polymerase dislocates during the elongation step and initiates synthesis at a homologous sequence (sometimes as short as three adenines) on another template [51]. Such artifacts in RNA virus detection by Nanopore sequencing have been reported [52]. To overcome these problemes, cDNA synthesis using random hexamers can be an appropriate alternative procedure [53].

Another nanopore sequencing kit that has recently attracted more attention is the direct RNA sequencing kit. The association of motor protein, as the regulator of the nucleic acid molecule 
translocation, with the RNA molecule indicates the low translocation velocity of RNA through the nanopore protein, which means the passing speed of RNA within the nanopore is slow enough to be measured and sequenced. Consequently, using algorithms adapted to this platform, current intensity fluctuations induced by the passage of RNA molecules through the nanopore can be converted into sequence information [54,55].

In contrast to the direct cDNA sequencing kit, the cDNA synthesis step (the first strand of cDNA) is optional for direct RNA sequencing. After the ligation of a double-stranded RT Adapter (RTA) and RNA sequencing adapter (RMX), native RNA can be sequenced directly [55]. Nevertheless, first-strand cDNA synthesis is recommended to resolve the structural complexity of RNA molecules and prevent the production of different-sized fragment reads during sequencing. When an RNA has a complex structure, the nanopore protein may be blocked, and the sequencing will stall [56]. Additional obstacles encountered with direct RNA sequencing compared to direct cDNA sequencing include lower throughput [57], higher sequencing error rate [58], and a lack of commercial barcodes for multiplexing. However, a new method, DeePlexiCon, has recently been described for barcoding and demultiplexing direct RNA sequencing libraries [55].

As a common limitation among all nanopore sequencing kits, high sequencing error rates limit the accurate characterization of quasi-species, new strains or subtypes of a virus and de novo assembly of viral reads $[46,59,60]$. In a given infected plant, closely related viral strains can be present with high average nucleotide identity (NI), and the assembly of individual strains present in low abundance or with low variation is complicated and challenging [61,62]. Even so, the capability of direct RNA sequencing kit for identifying viral strains with $20 \%$ to $40 \%$ divergence in term of NI has been demonstrated [63]. In addition, Haploflow, a new strain-resolving assembler, has been described, which considers the differential coverage between strains to deconvolute the assembly graph into strain resolved genome assemblies and has been used to reconstruct viral strain genomes from human cytomegalovirus positive samples and SARS-CoV2 wastewater samples [61]. Also, using the full reference sequence of the virus and a BLAST search with phylogeny is recommended for viral phylogeny and viral variation studies [60]. For studying genetic recombination, adaptive evolution, or resistance-breaking mutations in plant virology, nanopore sequencing is less than ideal until improvements in error rates are developed [46]. However, this technology is still an interesting option for virus detection from a variety of biological samples. 

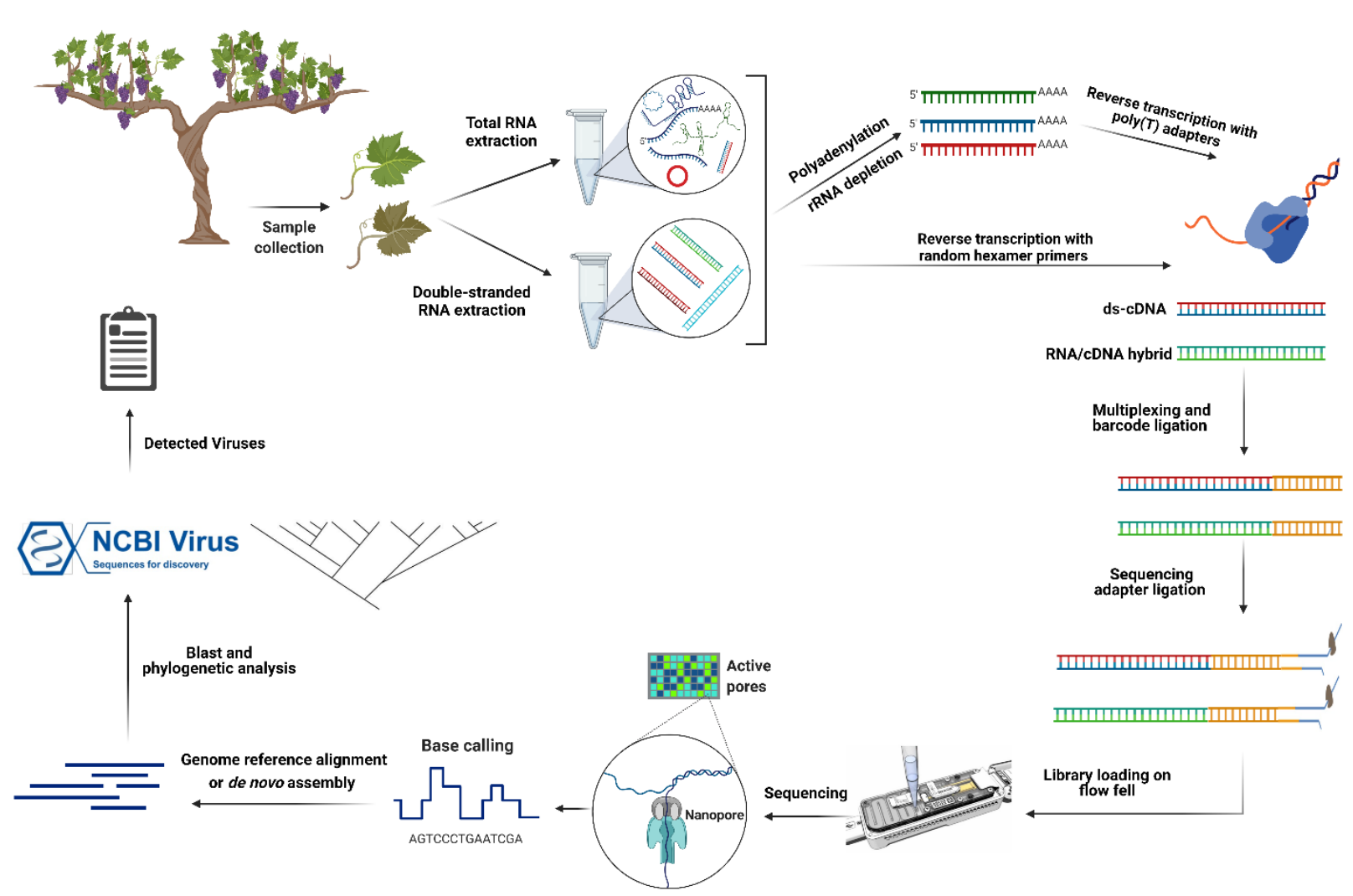

Figure 2. Illustration of the principle of nanopore direct cDNA and RNA sequencing for grapevine RNA virus detection. In direct RNA sequencing, after total RNA extraction, rRNAs are depleted using specific probes. To capture non-poly(A) viral RNAs, polyadenylation is performed. The first strand of cDNA is transcribed by using poly(T) adapters. In addition, different barcodes can be used to multiplex several libraries and sequence them using one flow cell. Then, the sequencing adapter is ligated, and the library (or pooled libraries) is loaded onto a flow cell. Finally, the sequencing step is run by setting up different options in MinKNOW software. After basecalling, downstream analysis steps are performed, and the list of detected viruses is extracted. In direct cDNA sequencing, after dsRNA extraction, double-stranded cDNAs are synthesized with random hexamer primers, and the subsequent steps are similar to direct RNA sequencing. Created with BioRender.com.

\section{Detection of grapevine DNA viruses by nanopore ligation and rapid sequencing}


Since several single-stranded DNA viruses, such as GRBV, and double-stranded DNA viruses, such as GVCV, can infect grapevines, two library preparation kits, ligation and rapid sequencing, are available for detecting them. Indeed, similar viruses, such as Cowpea bright yellow mosaic virus (CoBYMV) and African cassava mosaic virus (ACMV) have been detected using ligation and rapid sequencing kits, respectively [40,42]. Although both sequencing kits can be used for detecting DNA viruses, the throughput of rapid sequencing is lower (25\% lower) than ligation sequencing. However, the library preparation time for rapid sequencing is much shorter ( $\sim 10$ minutes) than ligation sequencing ( $\sim 60$ minutes), and the amount of input material necessary for this kit is lower (400 ng DNA) than the ligation sequencing kit (1000 ng DNA) [64].

\section{Adaptive nanopore sequencing for real-time virus detection}

For real-time detection of known viruses, adaptive sequencing by nanopore sequencing devices is possible. In this kind of sequencing, through partial mapping reads against desirable reference genomes, undesired reads can be ejected from the nanopore through provisionally reversing the voltage, and only targeted sequences are sequenced $[65,66]$. Adaptive sequencing can be done by mapping raw signals [66] or basecalled data against reference genomes [67]. Sufficient computing power (especially GPU power) is needed for basecalling. Therefore, raw signal mapping tools, such as Sigmap [66], can be used for fast and on-site virus detection. This kind of sequencing reduces sequencing costs and laborious library preparation for detecting pathogens such as viruses quickly.

\section{Viroids and virusoids}

There are various infectious long non-coding RNAs that originated from viruses or viroids. Viroids are single-stranded circular non-coding RNAs that are the smallest infectious entities (between 246 to $401 \mathrm{nt}$ in length) of plants and do not encode any protein. Viroids can replicate individually in the host plant nucleus or chloroplast by using host RNA polymerases through asymmetric and symmetric rolling-circle mechanisms [68]. Although many viroids were initially identified by the appearance of their symptoms on infected plants, it is now known that viroids can also infect hosts asymptomatically [69]. Like viruses, viroid-derived small RNAs (vd-sRNAs) accumulate in infected plant tissues and can be used to detect viroids [70].

As minor mutations in viroid sequences can dramatically affect the viroid movement [71], sequencing the full length of viroids will help us better understand their functionality and 
pathogenicity in the grapevine. So far, seven different viroid species from the Pospiviroidae family, such as Hop stunt viroid, Australian grapevine viroid, Grapevine latent viroid, and Grapevine yellow speckle viroid-1,2,3 and a tentative and an unclassified viroid, Grapevine hammerhead viroid-like RNA, have been identified in grapevines [72,73]. Grapevine viroids do not induce severe symptoms in grapevines singly unless in particular environmental conditions. They can cause severe symptoms in other host plants and be the primary disease agents. They seem to play a role in some viral disease through coinfection with other grapevine viruses $[69,74]$. Therefore, molecular, biological, and epidemiological analysis of grapevine viroids and viroidlike RNAs is needed.

Like viroids, virusoids (or small circular satellite RNAs) are other circular, long non-coding RNAs ranging from 220 to $457 \mathrm{nt}$ in length. Virusoids replicate through a rolling circle mechanism based on RNA intermediates and are dependent on helper viruses or host plants. In contrast to viroids, virusoids are encapsidated by the helper virus coat protein [68,75]. The similarities between viroids and virusoids have led to the hypothesis that these circular RNAs may have a monophyletic origin [75]. Several contradictory biological functions have been attributed to virusoids; for example, a virusoid decreased the accumulation of Tobacco ringspot virus (TRSV) as a helper virus and attenuated the symptoms in infected tobacco samples [76]. In contrast, some virusoids produce small RNAs (21-24 nt) similar to microRNAs and small interfering RNAs, downregulate some host mRNAs, and are involved in pathogenesis. Helper viruses of identified virusoids are from genera Sobemovirus, Polerovirus Nepovirus, and Polerovirus [75]. Since viroids and virusoids are circular, their identification and detection by nanopore sequencing is similar to circRNA detection, which is describe in the following section.

\section{Identification of long non-coding RNAs (IncRNAs) and circular RNAs (circRNAs)}

Recently, the function of long non-coding RNAs (lncRNA) and circular RNA (circRNA) as new RNA regulators in plant developmental processes and stress responses, especially in plantvirus interactions, has been studied [77]. Long non-coding RNAs are transcribed by RNA polymerase II, III, IV, and V [78-80] and are longer than $200 \mathrm{nt}$ [81]. There are five main categories of lncRNAs: intronic, intergenic, sense, bidirectional, and natural antisense lncRNAs [82]. So far, many lncRNAs have been identified in different plants such as watermelon [77], maize [78], Arabidopsis [83], rice, tomato [84,85], melon [86], cucumber [87], and Chinese cabbage [88]. 
However, there are limited studies about the function of lncRNAs in plant-virus interactions. For instance, through HTS, Sun et al. (2020) identified 2,373 lncRNAs and 606 circRNAs in watermelon infected with cucumber green mottle mosaic virus (CGMMV). A total of 67 lncRNAs and 548 circRNAs were upregulated or downregulated compared to CGMMV-free watermelon plants. For 49 differentially expressed (DE) lncRNAs, 263 cis-acting (their activity is based and dependent on their sites of transcription) matched lncRNA-mRNA pairs were detected. In addition, 33 microRNAs were matched with 30 DE-lncRNAs as putative target mimics. mRNAs that were predicted to interact with lncRNAs were associated with phenylalanine metabolism, tricarboxylic acid cycle (TCA cycle), and endocytosis pathways. In another study, during turnip crinkle virus (TCV) infection in Arabidopsis, the expression of the floral structure-related APETALA2 (AP2) gene was negatively correlated with its neighboring long intergenic noncoding RNAs (lincRNA), At4NC069370 [89]. In tomato infected with tomato yellow leaf curl virus (TYLCV), many differentially expressed lncRNAs were identified, and several studies investigated the function of various DE-lncRNAs in tomato-TYLCV interaction. For example, through virus-induced gene silencing and reduction of lncRNA S-slylnc0957 expression, the resistance of susceptible tomato plants to TYLCV was increased [84], [90] and disease development during TYLCV infection was controlled by interacting lncRNA SILNR1 with viral small interfering RNAs [91].

Circular RNAs (circRNAs), as single-stranded and stress-inducible RNAs, are generated by rare back-splicing events from precursor mRNAs (Pre-mRNAs). In a back-splicing event, an upstream $3^{\prime}$ splice site is ligated to a downstream 5' splice site through a 3'-5' phosphodiester bond [92,93]. circRNAs can originate from exonic, intronic, and intergenic regions of genomes [94,95]. Their expression depends on tissue and cell type, developmental stages, and biotic or abiotic stresses [86,96-98]. Although, until now, 142,115 cricRNAs in 20 plant species have been reported and deposited in PlantcircBase [90], the functionality of plant circRNAs is still unknown and understudied. Several recent studies have indicated that circRNAs could be miRNA sponges or competing endogenous RNAs and regulate the expression of paternal genes through alternative splicing events $[99,100]$. However, less attention has been paid to the potential function of circRNAs in plant-virus interactions. Through RNA sequencing and bioinformatics tools, 33 circRNAs were identified in maize infected with Maize Iranian mosaic virus (MIMV) and expected to bind to 23 maize miRNAs, possibly affecting plant metabolism and development [101]. In tomato yellow leaf curl virus (TYLCV) infected plant, 51 circRNAs were differentially 
expressed, and the accumulation of TYLCV was decreased through the silencing of these circRNAs parent genes [84]. In addition, a recent study indicated that 277 upregulated and 271 downregulated circRNAs are involved in watermelon CGMMV infected plants, and 153 of those circRNAs were putative target mimics of 88 watermelon miRNAs [77]. In grapevine, from 10 developmental stages of leaf, inflorescence, and berry tissues, 56,441 lncRNAs were identified that regulated developmental transitions and were involved in biosynthetic and secondary metabolic pathways, photosynthesis and oxidative phosphorylation [102]. In addition, by using different circRNA prediction algorithms, grapevine circRNA biogenesis was investigated, and 475 differentially expressed circRNAs during cold stress in grapevine leaves were identified. The cold tolerance in transgenic Arabidopsis plants was improved by overexpression of a circRNA derived from glycerol-3-P acyltransferase gene, Vv-circATS1 [86]. Since circRNAs are involved in different biological processes and have specific expression patterns under biotic and abiotic stresses, their potential regulatory roles at the transcriptional and post-transcriptional levels during virus infection should be investigated more. So far, their function as miRNA sponges has been identified. In addition, circRNA interact with many different RNA-binding proteins (RBPs), which could potentially affect viruses and gene regulation [103]. Therefore, there is a need to investigate the roles of lncRNAs and circRNAs in grapevine's response to viral infection. This area will open a new window in grapevine virology and disease management.

Although many lncRNAs and circRNAs have been identified by the advent of short-read sequencing [104], the prediction of different isoforms and splice events cannot be achieved accurately by short-read sequencing [105]. In addition, intergenic and intronic regions that originated from insertions or remnants of transposable elements (TE) are the source of various lncRNAs, and the association of IncRNAs with these kinds of repetitive sequences such as TEs have been suggested [106,107]. Until now, many bioinformatics pipelines have ignored ambiguously mapped reads in lncRNA identification, and the annotation of many lncRNAs is made challenging by the use of short-read sequencing [106,108]. Recently, long-read sequencing has allowed the sequencing of full-length RNA molecules and identification of 796 triticale lncRNAs and hundreds of unknown genic and intergenic lncRNAs. It was also possible to determine the association of these lncRNAs with the remnants of Class I and Class II transposable elements [106]. However, in this study, the presence of non-poly(A) lncRNAs was not considered. Alternatively, Saville et al. (2021) reported that a modified nanopore sequencing protocol, NERD- 
seq, can capture and sequence many poly(A) and non-polyadenylated RNAs and non-coding RNAs. This technique allows the comprehensive study of the epitranscriptome by using nanopore direct RNA sequencing. Briefly, in this protocol, total extracted RNAs were split into two different-sized fractions, long and short RNA fractions, by a column-based size enrichment approach. Poly(A) tailing was performed on the short-sized fraction to keep the nonpolyadenylated RNAs in the sequencing library; however, the poly(A) tailing process improves the accuracy of short-read sequencing by nanopore sequencing. In long-sized fractions, rRNA depletion was performed, and then two fractions were pooled together [109]. One of the main problems in nanopore direct RNA sequencing is the inhibition of the sequencing process by highly structured RNA regions [109,110], which may inhibit the pulling of the RNA molecule through the nanopore. An alternative solution is first-strand cDNA synthesis through reverse transcription. Although the first-strand cDNA is not sequenced, it improves the stability of the RNA strand during the sequencing step and resolves highly structured RNA regions in non-coding RNAs [111]. Based on the nanopore direct RNA sequencing manufacturer's protocol, the reverse transcription is done at between $45^{\circ} \mathrm{C}$ and $50^{\circ} \mathrm{C}$, and some highly structured non-coding RNAs are not transcribed at this temperature [109]. Therefore, the reverse transcription process is interrupted, and cDNAs of different lengths are produced. In the NERD-seq procedure, two-step reverse transcription is used to solve this problem. This procedure simplifies the RNA unfolding through OmniAmp, a loop-mediated isothermal amplification polymerase with random primers for initial reverse transcription at $70^{\circ} \mathrm{C}$ to produce the small first-strand cDNA fragments. After that, these small cDNA fragments are displaced by the cDNA strand of poly(T) reverse transcription [109]. This methodology gives this opportunity to characterize many kinds of non-coding RNAs involved in grapevine-virus interactions and to investigate the regulatory gene networks affected by viral infection (Figure 3). 


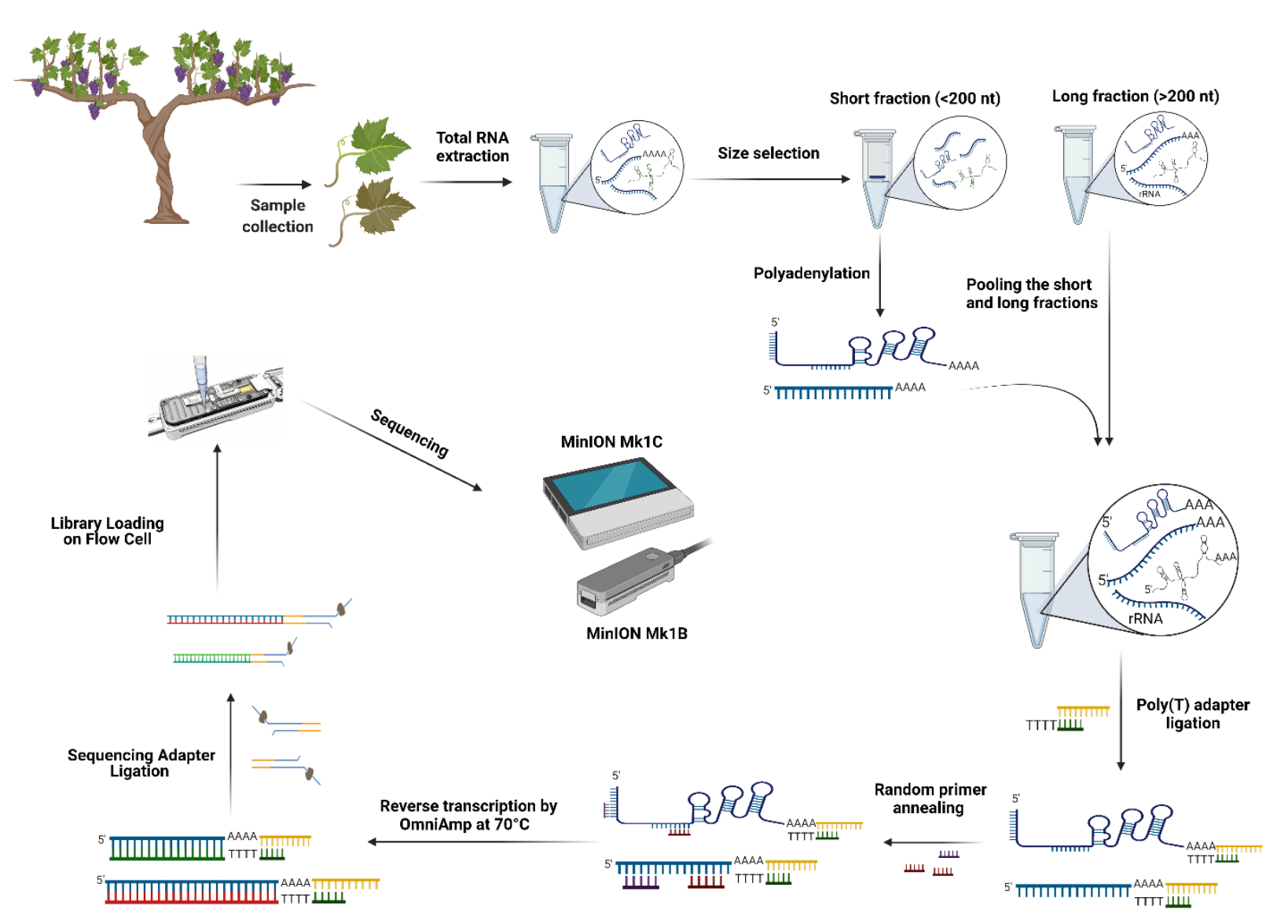

Figure 3. Non-coding RNAs and poly(A) tail RNAs sequencing in infected grapevine samples by nanopore direct RNA sequencing. Created with BioRender.com.

Concurrent with the advancement in next-generation sequencing, many circRNAs in plants have been characterized by various algorithms and bioinformatics tools, such as CIRI [112], KNIFE [113], and CIRCexplorer [114]. Most circRNA identification tools are based on short reads alignment. A large number of circRNAs originate from exonic regions, which makes distinguishing circRNAs from overlapping regions of their pre-mRNAs challenging [89,115]. Hence, long-read sequencing by nanopore can be used for plant circRNAs characterization and exploited to identify infectious circular RNAs such as viroids and virusoids from infected grapevine samples (Figure 4).

Two interesting library preparation methodologies for circRNAs sequencing based on nanopore direct RNA and cDNA sequencing are introduced in the following section. A novel library preparation procedure was reported in a recent study to characterize 470 unique circRNAs and their N6-methyladenosine (m6A) modifications in moso bamboo (Phyllostachys edulis) by 
using nanopore direct RNA sequencing. Concisely, extracted total RNAs were treated with RNase $\mathrm{R}$ to remove linear RNAs. Since the digestion of linear RNAs was not entirely achieved by RNase $\mathrm{R}$ treatment, poly(A) tailing was performed to deplete the remaining linear RNAs through oligo $(\mathrm{dT})_{25}$ beads. In the next step, rRNAs were depleted, and then the purified circRNAs were fragmented and dephosphorylated. Finally, after first-strand cDNA synthesis using a customized RT adapter containing degenerate primers, the sequencing adapter was ligated. Although this library preparation approach successfully identified circRNAs and their m6A modifications, the low sequencing depth of nanopore direct RNA sequencing remained the main obstacle for quantitative analysis [116]. Moreover, the fragmentation step in this protocol produces different sizes of fragments (especially short reads), which reduces pore viability, motor protein fuel reserves, and overall yield [109]. Consequently, higher enrichment of circRNAs can be achieved through fragment size selection. In one study, the portion of the full length of circRNAs in a library without a size selection step was $1 \%$, while in medium and long selected-fragment libraries, threefold and six-fold more full-length circRNA were captured, respectively [115]. 


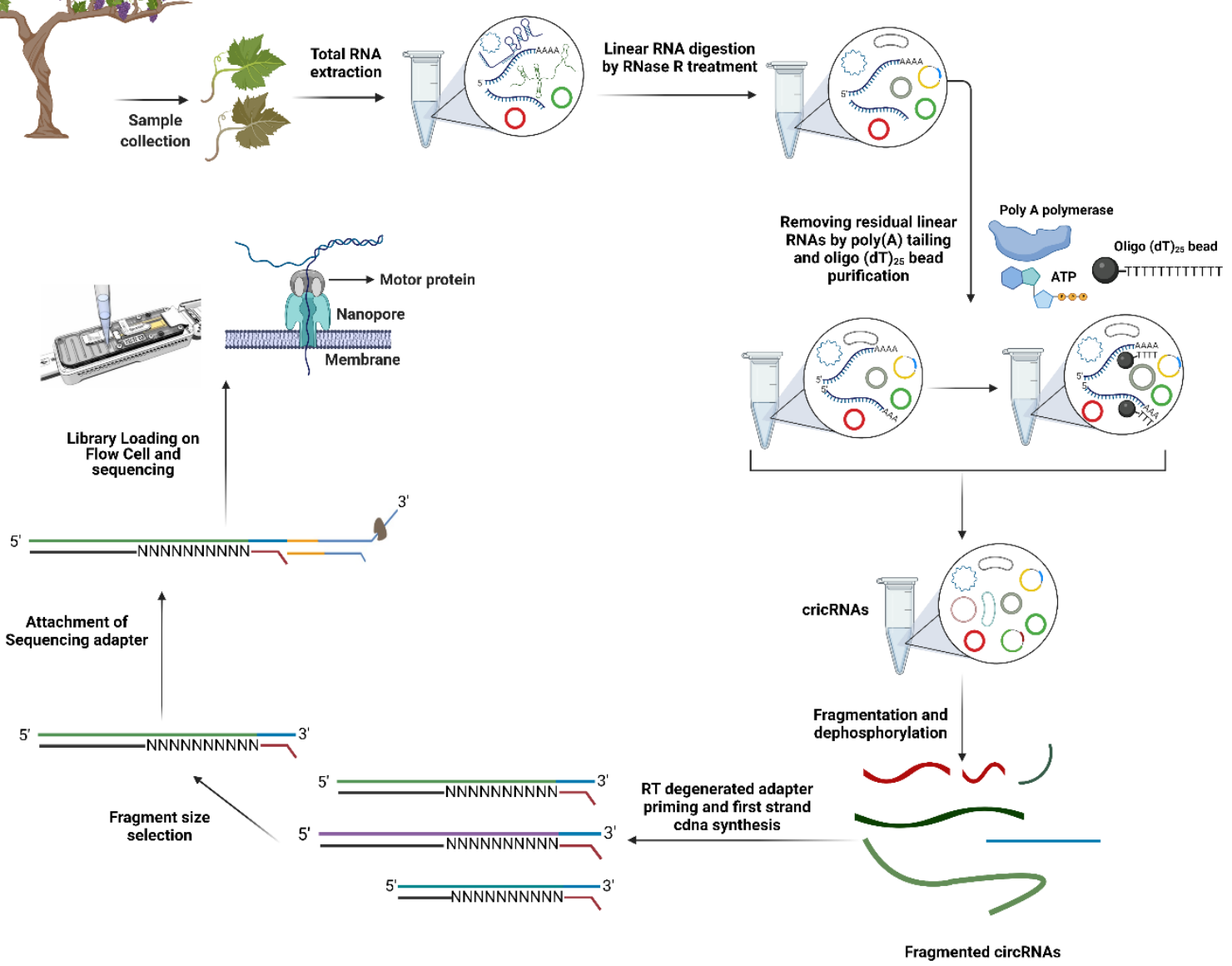

Figure 4. Detection of circular RNAs, viroids, and virusoids in infected grapevine samples by nanopore direct RNA sequencing. Created with BioRender.com.

In contrast to the above library preparation protocol, a recent study showed the application of nanopore cDNA sequencing for identifying various kinds of circRNAs in mouse brain samples [115]. In this protocol, the chemical fragmentation of circRNAs was omitted, and ds-cDNAs of circular RNAs were sequenced. After total RNA extraction, rRNA depletion, poly(A) tailing, and digestion of linear RNAs were performed. Reverse transcription was performed with random primers and cDNA amplification, followed by a fragment size (400 bp, $600 \mathrm{bp}$, and $1000 \mathrm{bp}$ ) selection with magnetic beads. Finally, library preparation and sequencing adapter ligation were done sequentially. The library was primed on a flow cell (R9) and sequenced using the MinION platform. In this study, the library preparation protocols were suitable for identifying different 
known types of circRNAs in mouse brain samples. A novel algorithm, CIRI-long, was used to construct a new type of intronic self-ligated circRNA [115].

\section{Detection of viral RNA modifications by nanopore sequencing}

Recently, a novel area in virology, viral RNA epitranscriptomics, has been investigated with the advent of new RNA modification site mapping techniques, such as nanopore direct RNA sequencing. Many questions about the functionality of these RNA modifications have been raised. RNA modifications appear through adding biochemical groups, such as a methyl group, to adenosine, cytosine, uracil, and guanosine nucleotides [117]. Although many studies have been done for mapping the various RNA modifications, such as N6-methyladenosine (m6A), 5methylcytidine $(5 \mathrm{mC})$, or N4-acetylcytidine $\left(\mathrm{ac}^{4} \mathrm{C}\right)$ on eukaryote mRNAs [117,118], viral RNA modifications have received little investigation. However, RNA modifications of viral RNAs do appear to be important. For instance, m6A on HIV-1 mRNA can modulate HIV-1 gene expression and affects the HIV-1 RNA stability and exportation of its RNA from nucleus [119]. In addition, m6A not only can decrease virus pathogenicity in Influenza virus but also promotes infection kinetics $[119,120]$. Likewise, ablation of an RNA demethylase in Arabidopsis resulted in increased m6A methylation of alfalfa mosaic virus RNA. This correlated with reduced systemic spread of the virus, suggesting that viral RNA methylation dynamics may play an important role in virus infections in plants [121]. Until now, nine RNA modification types on RNA or DNA human viruses have been mapped through antibody, protein CLIP (Class II-associated invariant chain peptide), biological and nanopore mapping procedures. For instance, nanopore direct RNA sequencing technology was used to identify $5 \mathrm{mC}$ methylation sites on the human coronavirus genome through the bioinformatics tool called Tombo [122]. Also, several bioinformatics tools, such as EpiNano, MINES, Nanocompore, and ELIGOs, have been developed for profiling m6A modification sites on different types of RNAs by using Nanopore sequencing data [123,124]. In addition to the identification of RNA modifications on viral RNAs, several functions in biological events, such as viral RNA trafficking, degradation of viral RNA, splicing of viral RNA, and immune evasion by viral RNA, have been proposed [117]. The continuous improvement of nanopore sequencing in the near future will allow researchers to answer many questions about biological processes in plant virology and help to understand how RNA modifications of viral genomes can influence their host as well as their new variants or other viruses. 


\section{Perspectives}

Through the advent of nanopore sequencing, a new way to sequence and quantify RNA and DNA has been established. Soon, nanopore technology will have a tremendous impact on plant virus detection, RNA modification research, plant epigenomics, epitranscriptomics, and other aspects of plant biology and virology. The sequencing error rate of this technology initially was significantly higher than other high-throughput sequencers. However, the technology is being continuously improved to increase accuracy by optimizing new nanopore proteins and motor proteins, designing new basecalling algorithms, changing the chemistry of library preparation kits, and testing a new sequencing orientation (Outy). This technology is a cost- and time-effective method for addressing various aspects of grapevine virology, such as massively parallel sequencing (MPS), grapevine virus detection, virus-plant interactions, and viral RNA modifications. Although a number of challenges, such as error correction and base modification detection, need to be resolved, the valuable potential of nanopore technology in grapevine virology should not be overlooked.

\section{References}

1. Statistical report on world vitiviniculture; International Organization of Vine and Wine: 2019.

2. Alston, J.M.; Sambucci, O. Grapes in the world economy. In The grape genome, Cantu, D.; Walker, M.A., Eds. Springer International Publishing: Cham, 2019; pp 1-24.

3. Robinson, J.; Harding, J.; Vouillamoz, J. Wine grapes: A complete guide to 1,368 vine varieties, including their origins and flavours. Penguin UK: 2013.

4. Sastry, K.S.; Zitter, T.A. Management of virus and viroid diseases of crops in the tropics. In Plant virus and viroid diseases in the tropics: Volume 2: Epidemiology and management, Sastry, K.S.; A. Zitter, T., Eds. Springer Netherlands: Dordrecht, 2014; pp 149-480.

5. $\quad$ Ricketts, K.D.; Gomez, M.I.; Atallah, S.S.; Fuchs, M.F.; Martinson, T.E.; Battany, M.C.; Bettiga, L.J.; Cooper, M.L.; Verdegaal, P.S.; Smith, R.J. Reducing the economic impact of grapevine leafroll disease in california: Identifying optimal disease management strategies. American Journal of Enology and Viticulture 2015, ajev.2014.14106.

6. Martelli, G.P. Directory of virus and virus-like diseases of the grapevine and their agents. Journal of Plant Pathology 2014, 96, 1-136.

7. Al Rwahnih, M.; Rowhani, A.; Golino, D. First report of grapevine red blotch-associated virus in archival grapevine material from sonoma county, california. Plant Disease 2015, 99, 895-895.

8. Basso, M.F.; Fajardo, T.V.; Saldarelli, P. Grapevine virus diseases: Economic impact and current advances in viral prospection and management. Revista Brasileira de Fruticultura 2017, 39, 1-22. 
9. Fuchs, M. Grapevine viruses: A multitude of diverse species with simple but overall poorly adopted management solutions in the vineyard. Journal of Plant Pathology 2020, 102, 643653.

10. Giampetruzzi, A.; Roumi, V.; Roberto, R.; Malossini, U.; Yoshikawa, N.; La Notte, P.; Terlizzi, F.; Credi, R.; Saldarelli, P. A new grapevine virus discovered by deep sequencing of virus- and viroid-derived small rnas in cv pinot gris. Virus Research 2012, 163, 262268.

11. Wallingford, A.K.; Fuchs, M.F.; Martinson, T.; Hesler, S.; Loeb, G.M. Slowing the spread of grapevine leafroll-associated viruses in commercial vineyards with insecticide control of the vector, pseudococcus maritimus (hemiptera: Pseudococcidae). J Insect Sci 2015, 15, 112-112.

12. Mahlein, A.-K. Plant disease detection by imaging sensors - parallels and specific demands for precision agriculture and plant phenotyping. Plant Disease 2015, 100, 241-251.

13. Bendel, N.; Kicherer, A.; Backhaus, A.; Köckerling, J.; Maixner, M.; Bleser, E.; Klück, H.-C.; Seiffert, U.; Voegele, R.T.; Töpfer, R. Detection of grapevine leafroll-associated virus 1 and 3 in white and red grapevine cultivars using hyperspectral imaging. Remote Sensing 2020, 12.

14. Blouin, A.G.; Chooi, K.M.; Cohen, D.; MacDiarmid, R.M. Serological methods for the detection of major grapevine viruses. In Grapevine viruses: Molecular biology, diagnostics and management, Meng, B.; Martelli, G.P.; Golino, D.A.; Fuchs, M., Eds. Springer International Publishing: Cham, 2017; pp 409-429.

15. Borges, D.F.; Preising, S.; Ambrósio, M.M.d.Q.; da Silva, W.L. Detection of multiple grapevine viruses in new england vineyards. Crop Protection 2020, 132, 105143.

16. Yadav, N.; Khurana, S.M.P. Plant virus detection and diagnosis: Progress and challenges. In Frontier discoveries and innovations in interdisciplinary microbiology, Shukla, P., Ed. Springer India: New Delhi, 2016; pp 97-132.

17. Varma, A.; Singh, M.K. Chapter 6 - diagnosis of plant virus diseases. In Applied plant virology, Awasthi, L.P., Ed. Academic Press: 2020; pp 79-92.

18. Celia Chalam, V.; Sharma, V.D.; Sharma, R.; Maurya, A.K. Chapter 5 - modern technologies for the diagnosis and assay of plants viruses. In Applied plant virology, Awasthi, L.P., Ed. Academic Press: 2020; pp 69-77.

19. Zherdev, A.V.; Vinogradova, S.V.; Byzova, N.A.; Porotikova, E.V.; Kamionskaya, A.M.; Dzantiev, B.B. Methods for the diagnosis of grapevine viral infections: A review. Agriculture 2018, 8 .

20. Notomi, T.; Okayama, H.; Masubuchi, H.; Yonekawa, T.; Watanabe, K.; Amino, N.; Hase, T. Loop-mediated isothermal amplification of DNA. Nucleic Acids Research 2000, 28, e63-e63.

21. Walsh, H.A.; Pietersen, G. Rapid detection of grapevine leafroll-associated virus type 3 using a reverse transcription loop-mediated amplification method. Journal of Virological Methods 2013, 194, 308-316.

22. Almasi, M. Establishment and application of a reverse transcription loop-mediated isothermal amplification assay for detection of grapevine fanleaf virus. Molecular Biology 2015, 4.

23. Hadidi, A.; Czosnek, H.; Barba, M. DNA microarrays and their potential applications for the detection of plant viruses, viroids, and phytoplasmas. Journal of Plant Pathology 2004, 86, 97-104. 
24. Engel, E.A.; Escobar, P.F.; Rojas, L.A.; Rivera, P.A.; Fiore, N.; Valenzuela, P.D.T. A diagnostic oligonucleotide microarray for simultaneous detection of grapevine viruses. Journal of Virological Methods 2010, 163, 445-451.

25. Al Rwahnih, M.; Daubert, S.; Golino, D.; Rowhani, A. Deep sequencing analysis of rnas from a grapevine showing syrah decline symptoms reveals a multiple virus infection that includes a novel virus. Virology 2009, 387, 395-401.

26. Fall, M.L.; Xu, D.; Lemoyne, P.; Moussa, I.E.B.; Beaulieu, C.; Carisse, O. A diverse virome of leafroll-infected grapevine unveiled by dsrna sequencing. Viruses 2020, 12.

27. Maliogka, V.I.; Olmos, A.; Pappi, P.G.; Lotos, L.; Efthimiou, K.; Grammatikaki, G.; Candresse, T.; Katis, N.I.; Avgelis, A.D. A novel grapevine badnavirus is associated with the roditis leaf discoloration disease. Virus Research 2015, 203, 47-55.

28. Zhang, Y.; Singh, K.; Kaur, R.; Qiu, W. Association of a novel DNA virus with the grapevine vein-clearing and vine decline syndrome. Phytopathology® 2011, 101, 10811090.

29. Pop, M.; Salzberg, S.L. Bioinformatics challenges of new sequencing technology. Trends in Genetics 2008, 24, 142-149.

30. Roossinck, M.J.; Martin, D.P.; Roumagnac, P. Plant virus metagenomics: Advances in virus discovery. Phytopathology® 2015, 105, 716-727.

31. Zhong, Y.; Xu, F.; Wu, J.; Schubert, J.; Li, M.M. Application of next generation sequencing in laboratory medicine. Ann Lab Med 2021, 41, 25-43.

32. Hu, T.; Chitnis, N.; Monos, D.; Dinh, A. Next-generation sequencing technologies: An overview. Human Immunology 2021.

33. Eid, J.; Fehr, A.; Gray, J.; Luong, K.; Lyle, J.; Otto, G.; Peluso, P.; Rank, D.; Baybayan, P.; Bettman, B., et al. Real-time DNA sequencing from single polymerase molecules. Science 2009, 323, 133.

34. Wenger, A.M.; Peluso, P.; Rowell, W.J.; Chang, P.-C.; Hall, R.J.; Concepcion, G.T.; Ebler, J.; Fungtammasan, A.; Kolesnikov, A.; Olson, N.D., et al. Accurate circular consensus long-read sequencing improves variant detection and assembly of a human genome. Nature Biotechnology 2019, 37, 1155-1162.

35. Kasianowicz, J.J.; Brandin, E.; Branton, D.; Deamer, D.W. Characterization of individual polynucleotide molecules using a membrane channel. Proc Natl Acad Sci U S A 1996, 93, 13770-13773.

36. Mikheyev, A.S.; Tin, M.M.Y. A first look at the oxford nanopore minion sequencer. Molecular Ecology Resources 2014, 14, 1097-1102.

37. Phannareth, T.; Nunziata, S.O.; Stulberg, M.J.; Galvez, M.E.; Rivera, Y. Comparison of nanopore sequencing protocols and real-time analysis for phytopathogen diagnostics. Plant Health Progress 2021, 22, 31-36.

38. Silvestre-Ryan, J.; Holmes, I. Pair consensus decoding improves accuracy of neural network basecallers for nanopore sequencing. Genome Biology 2021, 22, 38.

39. Chiapello, M.; Rodríguez-Romero, J.; Nerva, L.; Forgia, M.; Chitarra, W.; Ayllón, M.A.; Turina, M. Putative new plant viruses associated withplasmopara viticola-infected grapevine samples. Annals of Applied Biology 2020, 176, 180-191.

40. Boykin, L.M.; Sseruwagi, P.; Alicai, T.; Ateka, E.; Mohammed, I.U.; Stanton, J.-A.L.; Kayuki, C.; Mark, D.; Fute, T.; Erasto, J., et al. Tree lab: Portable genomics for early detection of plant viruses and pests in sub-saharan africa. Genes 2019, 10. 
41. Stenger, D.C.; Burbank, L.P.; Wang, R.; Stewart, A.A.; Mathias, C.; Goodin, M.M. Lost and found: Rediscovery and genomic characterization of sowthistle yellow vein virus after a 30+ year hiatus. Virus Research 2020, 284, 197987.

42. Naito, F.Y.B.; Melo, F.L.; Fonseca, M.E.N.; Santos, C.A.F.; Chanes, C.R.; Ribeiro, B.M.; Gilbertson, R.L.; Boiteux, L.S.; de Cássia Pereira-Carvalho, R. Nanopore sequencing of a novel bipartite new world begomovirus infecting cowpea. Archives of Virology 2019, 164, 1907-1910.

43. Bronzato Badial, A.; Sherman, D.; Stone, A.; Gopakumar, A.; Wilson, V.; Schneider, W.; King, J. Nanopore sequencing as a surveillance tool for plant pathogens in plant and insect tissues. Plant Disease 2018, 102, 1648-1652.

44. Fellers, J.P.; Webb, C.; Fellers, M.C.; Shoup Rupp, J.; De Wolf, E. Wheat virus identification within infected tissue using nanopore sequencing technology. Plant Disease 2019, 103, 2199-2203.

45. Chalupowicz, L.; Dombrovsky, A.; Gaba, V.; Luria, N.; Reuven, M.; Beerman, A.; Lachman, O.; Dror, O.; Nissan, G.; Manulis-Sasson, S. Diagnosis of plant diseases using the nanopore sequencing platform. Plant Pathology 2019, 68, 229-238.

46. Filloux, D.; Fernandez, E.; Loire, E.; Claude, L.; Galzi, S.; Candresse, T.; Winter, S.; Jeeva, M.L.; Makeshkumar, T.; Martin, D.P., et al. Nanopore-based detection and characterization of yam viruses. Scientific Reports 2018, 8, 17879.

47. Della Bartola, M.; Byrne, S.; Mullins, E. Characterization of potato virus y isolates and assessment of nanopore sequencing to detect and genotype potato viruses. Viruses 2020, 12 .

48. Kesanakurti, P.; Belton, M.; Saeed, H.; Rast, H.; Boyes, I.; Rott, M. Screening for plant viruses by next generation sequencing using a modified double strand rna extraction protocol with an internal amplification control. Journal of Virological Methods 2016, 236, 35-40.

49. Dodds, J.A.; Morris, T.J.; Jordan, R.L. Plant viral double-stranded rna. Annual Review of Phytopathology 1984, 22, 151-168.

50. Weber, F.; Wagner, V.; Rasmussen Simon, B.; Hartmann, R.; Paludan Søren, R. Doublestranded rna is produced by positive-strand rna viruses and DNA viruses but not in detectable amounts by negative-strand rna viruses. Journal of Virology 2006, 80, 50595064.

51. Balázs, Z.; Tombácz, D.; Csabai, Z.; Moldován, N.; Snyder, M.; Boldogkői, Z. Templateswitching artifacts resemble alternative polyadenylation. BMC Genomics 2019, 20, 824.

52. Moldován, N.; Tombácz, D.; Szücs, A.; Csabai, Z.; Balázs, Z.; Kis, E.; Molnár, J.; Boldogkői, Z. Third-generation sequencing reveals extensive polycistronism and transcriptional overlapping in a baculovirus. Scientific Reports 2018, 8, 8604.

53. Young, K.T.; Lahmers, K.K.; Sellers, H.S.; Stallknecht, D.E.; Poulson, R.L.; Saliki, J.T.; Tompkins, S.M.; Padykula, I.; Siepker, C.; Howerth, E.W., et al. Randomly primed, strandswitching, minion-based sequencing for the detection and characterization of cultured rna viruses. Journal of Veterinary Diagnostic Investigation 2021, 33, 202-215.

54. Rang, F.J.; Kloosterman, W.P.; de Ridder, J. From squiggle to basepair: Computational approaches for improving nanopore sequencing read accuracy. Genome Biology 2018, 19, 90. 
55. Smith, M.A.; Ersavas, T.; Ferguson, J.M.; Liu, H.; Lucas, M.C.; Begik, O.; Bojarski, L.; Barton, K.; Novoa, E.M. Molecular barcoding of native rnas using nanopore sequencing and deep learning. Genome Research 2020, 30, 1345-1353.

56. Boonham, N.; Walsh, K.; Smith, P.; Madagan, K.; Graham, I.; Barker, I. Detection of potato viruses using microarray technology: Towards a generic method for plant viral disease diagnosis. Journal of Virological Methods 2003, 108, 181-187.

57. Li, R.; Ren, X.; Ding, Q.; Bi, Y.; Xie, D.; Zhao, Z. Direct full-length rna sequencing reveals unexpected transcriptome complexity during caenorhabditis elegans development. Genome Research 2020, 30, 287-298.

58. Harel, N.; Meir, M.; Gophna, U.; Stern, A. Direct sequencing of rna with minion nanopore: Detecting mutations based on associations. Nucleic Acids Research 2019, 47, e148-e148.

59. Cao, Y.; Li, J.; Chu, X.; Liu, H.; Liu, W.; Liu, D. Nanopore sequencing: A rapid solution for infectious disease epidemics. Science China Life Sciences 2019, 62, 1101-1103.

60. Leigh, D.M.; Schefer, C.; Cornejo, C. Determining the suitability of minion's direct rna and DNA amplicon sequencing for viral subtype identification. Viruses 2020, 12.

61. Fritz, A.; Bremges, A.; Deng, Z.-L.; Lesker, T.R.; Götting, J.; Ganzenmueller, T.; Sczyrba, A.; Dilthey, A.; Klawonn, F.; McHardy, A.C. Haploflow: Strain-resolved de novo assembly of viral genomes. Genome Biology 2021, 22, 212.

62. Deng, Z.-L.; Dhingra, A.; Fritz, A.; Götting, J.; Münch, P.C.; Steinbrück, L.; Schulz, T.F.; Ganzenmüller, T.; McHardy, A.C. Evaluating assembly and variant calling software for strain-resolved analysis of large DNA viruses. Briefings in Bioinformatics 2021, 22.

63. Tan, S.; Dvorak, C.M.T.; Murtaugh, M.P. Rapid, unbiased prrsv strain detection using minion direct rna sequencing and bioinformatics tools. Viruses 2019, 11.

64. Alabi, O.J.; Appel, D.N.; McBride, S.; Al Rwahnih, M.; Pontasch, F.M. Complete genome sequence analysis of a genetic variant of grapevine virus 1 from the grapevine cultivar blanc du bois. Arch Virol 2020, 165, 1905-1909.

65. Loose, M.; Malla, S.; Stout, M. Real-time selective sequencing using nanopore technology. Nature methods 2016, 13, 751-754.

66. Zhang, H.; Li, H.; Jain, C.; Cheng, H.; Au, K.F.; Li, H.; Aluru, S. Real-time mapping of nanopore raw signals. Bioinformatics 2021, 37, i477-i483.

67. Payne, A.; Holmes, N.; Clarke, T.; Munro, R.; Debebe, B.J.; Loose, M. Readfish enables targeted nanopore sequencing of gigabase-sized genomes. Nature Biotechnology 2021, 39, 442-450.

68. Shrestha, N.; Bujarski, J.J. Long noncoding rnas in plant viroids and viruses: A review. Pathogens 2020, 9.

69. Xu, D.; Adkar-Purushothama, C.R.; Lemoyne, P.; Perreault, J.P.; Fall, M. First report of grapevine yellow speckle viroid 1 infecting grapevine (vitis vinifera 1.) in canada. Plant Disease 2021.

70. Flores, R.; Di Serio, F.; Navarro, B.; Duran-Vila, N.; Owens, R.A. Viroids and viroid diseases of plants. Studies in Viral Ecology 2021, 231-273.

71. Ding, B.; Kwon, M.-O.; Hammond, R.; Owens, R. Cell-to-cell movement of potato spindle tuber viroid. The Plant Journal 1997, 12, 931-936.

72. Adkar-Purushothama, C.R.; Perreault, J.-P. Current overview on viroid-host interactions. WIREs RNA 2020, 11, e1570. 
73. Rotunno, S.; Vaira, A.M.; Marian, D.; Schneider, A.; Raimondi, S.; Di Serio, F.; Navarro, B.; Miozzi, L. First report of grapevine latent viroid infecting grapevine (vitis vinifera) in italy. Plant Disease 2018, 102, 1672.

74. Di Serio, F.; Izadpanah, K.; Hajizadeh, M.; Navarro, B. Viroids infecting the grapevine. In Grapevine viruses: Molecular biology, diagnostics and management, Meng, B.; Martelli, G.P.; Golino, D.A.; Fuchs, M., Eds. Springer International Publishing: Cham, 2017; pp 373-392.

75. Navarro, B.; Rubino, L.; Di Serio, F. Chapter 61 - small circular satellite rnas. In Viroids and satellites, Hadidi, A.; Flores, R.; Randles, J.W.; Palukaitis, P., Eds. Academic Press: Boston, 2017; pp 659-669.

76. Chay, C.A.; Guan, X.; Bruening, G. Formation of circular satellite tobacco ringspot virus rna in protoplasts transiently expressing the linear rna. Virology 1997, 239, 413-425.

77. Sun, Y.; Zhang, H.; Fan, M.; He, Y.; Guo, P. Genome-wide identification of long noncoding rnas and circular rnas reveal their cerna networks in response to cucumber green mottle mosaic virus infection in watermelon. Archives of Virology 2020, 165, 1177-1190.

78. Li, L.; Eichten, S.R.; Shimizu, R.; Petsch, K.; Yeh, C.-T.; Wu, W.; Chettoor, A.M.; Givan, S.A.; Cole, R.A.; Fowler, J.E., et al. Genome-wide discovery and characterization of maize long non-coding rnas. Genome Biology 2014, 15, R40.

79. Wierzbicki, A.T.; Haag, J.R.; Pikaard, C.S. Noncoding transcription by rna polymerase pol $\mathrm{ivb} /$ pol v mediates transcriptional silencing of overlapping and adjacent genes. Cell 2008, 135, 635-648.

80. Wu, J.; Okada, T.; Fukushima, T.; Tsudzuki, T.; Sugiura, M.; Yukawa, Y. A novel hypoxic stress-responsive long non-coding rna transcribed by rna polymerase iii in arabidopsis. RNA Biology 2012, 9, 302-313.

81. Wang, H.; Chung, P.J.; Liu, J.; Jang, I.-C.; Kean, M.J.; Xu, J.; Chua, N.-H. Genome-wide identification of long noncoding natural antisense transcripts and their responses to light in arabidopsis. Genome Research 2014, 24, 444-453.

82. Mercer, T.R.; Dinger, M.E.; Mattick, J.S. Long non-coding rnas: Insights into functions. Nature Reviews Genetics 2009, 10, 155-159.

83. Ma, X.; Shao, C.; Jin, Y.; Wang, H.; Meng, Y. Long non-coding rnas: A novel endogenous source for the generation of dicer-like 1-dependent small rnas in arabidopsis thaliana. RNA Biol 2014, 11, 373-390.

84. Wang, J.; Yang, Y.; Jin, L.; Ling, X.; Liu, T.; Chen, T.; Ji, Y.; Yu, W.; Zhang, B. Reanalysis of long non-coding rnas and prediction of circrnas reveal their novel roles in susceptible tomato following tylcv infection. BMC Plant Biology 2018, 18, 104.

85. Wang, J.; Yu, W.; Yang, Y.; Li, X.; Chen, T.; Liu, T.; Ma, N.; Yang, X.; Liu, R.; Zhang, B. Genome-wide analysis of tomato long non-coding rnas and identification as endogenous target mimic for microrna in response to tylcv infection. Scientific Reports 2015, 5, 16946.

86. Gao, Z.; Li, J.; Luo, M.; Li, H.; Chen, Q.; Wang, L.; Song, S.; Zhao, L.; Xu, W.; Zhang, C., et al. Characterization and cloning of grape circular rnas identified the cold resistancerelated vv-circats1. Plant Physiology 2019, 180, 966-985.

87. He, X.; Guo, S.; Wang, Y.; Wang, L.; Shu, S.; Sun, J. Systematic identification and analysis of heat-stress-responsive lncrnas, circrnas and mirnas with associated co-expression and cerna networks in cucumber (cucumis sativus 1.). Physiologia Plantarum 2020, 168, 736754. 
88. Wang, A.; Hu, J.; Gao, C.; Chen, G.; Wang, B.; Lin, C.; Song, L.; Ding, Y.; Zhou, G. Genome-wide analysis of long non-coding rnas unveils the regulatory roles in the heat tolerance of chinese cabbage (brassica rapa ssp.Chinensis). Scientific Reports 2019, 9, 5002.

89. Gao, Y.; Wang, J.; Zheng, Y.; Zhang, J.; Chen, S.; Zhao, F. Comprehensive identification of internal structure and alternative splicing events in circular rnas. Nature Communications 2016, 7, 12060.

90. Chu, Q.; Bai, P.; Zhu, X.; Zhang, X.; Mao, L.; Zhu, Q.-H.; Fan, L.; Ye, C.-Y. Characteristics of plant circular rnas. Briefings in Bioinformatics 2020, 21, 135-143.

91. Yang, Y.; Liu, T.; Shen, D.; Wang, J.; Ling, X.; Hu, Z.; Chen, T.; Hu, J.; Huang, J.; Yu, $\mathrm{W}$., et al. Tomato yellow leaf curl virus intergenic sirnas target a host long noncoding rna to modulate disease symptoms. PLOS Pathogens 2019, 15, e1007534.

92. Ebbesen, K.K.; Hansen, T.B.; Kjems, J. Insights into circular rna biology. RNA biology 2017, 14, 1035-1045.

93. Ye, C.-Y.; Chen, L.; Liu, C.; Zhu, Q.-H.; Fan, L. Widespread noncoding circular rnas in plants. New Phytologist 2015, 208, 88-95.

94. Jeck, W.R.; Sharpless, N.E. Detecting and characterizing circular rnas. Nature Biotechnology 2014, 32, 453-461.

95. Lasda, E.; Parker, R. Circular rnas: Diversity of form and function. RNA 2014, 20, 18291842.

96. Li, G.-T.; Niu, Z.-M.; Zheng, Z.-Y.; Lv, J.-J.; Chen, Q.-Y.; Liu, J.-Q.; Wan, D.-S. Contrasting origins, expression patterns and functions of circrnas between salt-sensitive and salt-tolerant poplars. Environmental and Experimental Botany 2021, 185, 104403.

97. Pan, T.; Sun, X.; Liu, Y.; Li, H.; Deng, G.; Lin, H.; Wang, S. Heat stress alters genomewide profiles of circular rnas in arabidopsis. Plant Molecular Biology 2018, 96, 217-229.

98. Tong, W.; Yu, J.; Hou, Y.; Li, F.; Zhou, Q.; Wei, C.; Bennetzen, J.L. Circular rna architecture and differentiation during leaf bud to young leaf development in tea (camellia sinensis). Planta 2018, 248, 1417-1429.

99. Conn, V.M.; Hugouvieux, V.; Nayak, A.; Conos, S.A.; Capovilla, G.; Cildir, G.; Jourdain, A.; Tergaonkar, V.; Schmid, M.; Zubieta, C., et al. A circrna from sepallata3 regulates splicing of its cognate mrna through r-loop formation. Nature Plants 2017, 3, 17053.

100. Hansen, T.B.; Jensen, T.I.; Clausen, B.H.; Bramsen, J.B.; Finsen, B.; Damgaard, C.K.; Kjems, J. Natural rna circles function as efficient microrna sponges. Nature 2013, 495, 384-388.

101. Ghorbani, A.; Izadpanah, K.; Peters, J.R.; Dietzgen, R.G.; Mitter, N. Detection and profiling of circular rnas in uninfected and maize iranian mosaic virus-infected maize. Plant Science 2018, 274, 402-409.

102. Bhatia, G.; Sharma, S.; Upadhyay, S.K.; Singh, K. Long non-coding rnas coordinate developmental transitions and other key biological processes in grapevine. Scientific Reports 2019, 9, 3552.

103. Zhang, P.; Li, S.; Chen, M. Characterization and function of circular rnas in plants. Frontiers in Molecular Biosciences 2020, 7, 91.

104. Saleembhasha, A.; Mishra, S. Novel molecules lncrnas, trfs and circrnas deciphered from next-generation sequencing/rna sequencing: Computational databases and tools. Briefings in Functional Genomics 2018, 17, 15-25. 
105. Zhu, F.-Y.; Chen, M.-X.; Ye, N.-H.; Shi, L.; Ma, K.-L.; Yang, J.-F.; Cao, Y.-Y.; Zhang, Y.; Yoshida, T.; Fernie, A.R., et al. Proteogenomic analysis reveals alternative splicing and translation as part of the abscisic acid response in arabidopsis seedlings. The Plant Journal 2017, 91, 518-533.

106. Kirov, I.; Dudnikov, M.; Merkulov, P.; Shingaliev, A.; Omarov, M.; Kolganova, E.; Sigaeva, A.; Karlov, G.; Soloviev, A. Nanopore rna sequencing revealed long non-coding and ltr retrotransposon-related rnas expressed at early stages of triticale seed development. Plants (Basel) 2020, 9, 1794.

107. Palazzo, A.F.; Koonin, E.V. Functional long non-coding rnas evolve from junk transcripts. Cell 2020, 183, 1151-1161.

108. Lanciano, S.; Cristofari, G. Measuring and interpreting transposable element expression. Nature Reviews Genetics 2020, 21, 721-736.

109. Saville, L.; Cheng, Y.; Gollen, B.; Mitchell, L.; Stuart-Edwards, M.; Haight, T.; Mohajerani, M.; Zovoilis, A. Nerd-seq: A novel approach of nanopore direct rna sequencing that expands representation of non-coding rnas. bioRxiv 2021, 2021.2005.2006.442990.

110. Garalde, D.R.; Snell, E.A.; Jachimowicz, D.; Sipos, B.; Lloyd, J.H.; Bruce, M.; Pantic, N.; Admassu, T.; James, P.; Warland, A., et al. Highly parallel direct rna sequencing on an array of nanopores. Nature Methods 2018, 15, 201-206.

111. Boivin, V.; Deschamps-Francoeur, G.; Couture, S.; Nottingham, R.M.; BouchardBourelle, P.; Lambowitz, A.M.; Scott, M.S.; Abou-Elela, S. Simultaneous sequencing of coding and noncoding rna reveals a human transcriptome dominated by a small number of highly expressed noncoding genes. RNA 2018, 24, 950-965.

112. Gao, Y.; Wang, J.; Zhao, F. Ciri: An efficient and unbiased algorithm for de novo circular rna identification. Genome Biology 2015, 16, 4.

113. Szabo, L.; Morey, R.; Palpant, N.J.; Wang, P.L.; Afari, N.; Jiang, C.; Parast, M.M.; Murry, C.E.; Laurent, L.C.; Salzman, J. Statistically based splicing detection reveals neural enrichment and tissue-specific induction of circular rna during human fetal development. Genome Biology 2015, 16, 126.

114. Zhang, X.-O.; Wang, H.-B.; Zhang, Y.; Lu, X.; Chen, L.-L.; Yang, L. Complementary sequence-mediated exon circularization. Cell 2014, 159, 134-147.

115. Zhang, J.; Hou, L.; Zuo, Z.; Ji, P.; Zhang, X.; Xue, Y.; Zhao, F. Comprehensive profiling of circular rnas with nanopore sequencing and ciri-long. Nature Biotechnology 2021, 39, 836-845.

116. Wang, Y.; Wang, H.; Xi, F.; Wang, H.; Han, X.; Wei, W.; Zhang, H.; Zhang, Q.; Zheng, Y.; Zhu, Q., et al. Profiling of circular rna n6-methyladenosine in moso bamboo (phyllostachys edulis) using nanopore-based direct rna sequencing. Journal of Integrative Plant Biology 2020, 62, 1823-1838.

117. Courtney, D.G. Post-transcriptional regulation of viral rna through epitranscriptional modification. Cells 2021, 10.

118. Ito, S.; Horikawa, S.; Suzuki, T.; Kawauchi, H.; Tanaka, Y.; Suzuki, T.; Suzuki, T. Human NAT10 is an ATP-dependent RNA acetyltransferase responsible for N4-acetylcytidine formation in $18 \mathrm{~S}$ ribosomal RNA (rRNA). Journal of Biological Chemistry 2014, 289, 35724-35730.

119. Netzband, R.; Pager, C.T.J.W.I.R.R. Epitranscriptomic marks: Emerging modulators of rna virus gene expression. 2020, 11, e1576. 
120. Courtney, D.G.; Kennedy, E.M.; Dumm, R.E.; Bogerd, H.P.; Tsai, K.; Heaton, N.S.; Cullen, B.R. Epitranscriptomic enhancement of influenza a virus gene expression and replication. Cell Host \& Microbe 2017, 22, 377-386.e375.

121. Martínez-Pérez, M.; Aparicio, F.; López-Gresa, M.P.; Bellés, J.M.; Sánchez-Navarro, J.A.; Pallás, V. Arabidopsis $\mathrm{m}^{6}$ a demethylase activity modulates viral infection of a plant virus and the m6a abundance in its genomic rnas. Proceedings of the National Academy of Sciences 2017, 114, 10755.

122. Viehweger, A.; Krautwurst, S.; Lamkiewicz, K.; Madhugiri, R.; Ziebuhr, J.; Hölzer, M.; Marz, M. Direct rna nanopore sequencing of full-length coronavirus genomes provides novel insights into structural variants and enables modification analysis. Genome Research 2019, 29, 1545-1554.

123. Arribas-Hernández, L.; Brodersen, P. Occurrence and functions of m6a and other covalent modifications in plant mrna1 [open]. Plant Physiology 2020, 182, 79-96.

124. Reddy, A.S.N.; Huang, J.; Syed, N.H.; Ben-Hur, A.; Dong, S.; Gu, L. Decoding co-/posttranscriptional complexities of plant transcriptomes and epitranscriptome using nextgeneration sequencing technologies. Biochemical Society Transactions 2020, 48, 23992414. 